\title{
Worldview Struggles under a New Climate Regime
}

\section{South African and Norwegian Media Coverage of COP17}

\author{
Jill Johannessen ${ }^{1}$
}

\begin{abstract}
The UN summit on climate change in Durban constituted an important moment in the continuous discourse on how to understand climate change and the framing of the problems and solutions. A new emergent frame of understanding could be detected in the press, which the author calls the 'out-dated worldview' frame. This frame contains a critique of the clear-cut division between developing vs. developed countries from the 1992 Rio Convention, and may influence how we understand burden-sharing roles in a new global climate deal. In an eager attempt to include all major polluters within a new climate regime, there is a danger that the principle of 'common but differentiated responsibility' will be ignored, which may be an attempt to excuse the rich industrialized countries from their responsibility after 150 years of benefitting from fossil-fuel-driven development.
\end{abstract}

Keywords: climate deal, climate negotiations, COP17, Kyoto Protocol, climate framing, climate representations

\section{Introduction}

Climate change poses a fundamental challenge that exerts pressure to pursue change politically, economically and in daily life (e.g., Giddens 2009 and Hulme 2010). It has also become an era of struggle and contestation that calls forth our worldviews, norms and values. During the Seventeenth Conference of the Parties (COP17), which took place in Durban in 2011, this struggle was manifested in representations of worldviews under the presumption that the climate negotiations will be concluded with a new global climate deal some time in the future. The mass media constitute an important arena on which this struggle is taking place, as depicted in the following quotation from the State Secretary of the Norwegian Department of Finance:

The rich countries of yesterday, are not necessarily the rich countries of tomorrow. Today countries like Singapore and South Korea are defined as poor, while Bulgaria and Greece are placed in the category of rich nations in the Kyoto system. We can't base climate politics in this century on a worldview from the last century" (Ketil Lund, in Bergens Tidende 05.12.11; my translation).

The statement is a response to a global shift in geo-political influence and economic power from the Global North to the Global South that has taken place during the past couple of decades. Emerging economies, spearheaded by China, have experienced tre- 
mendous economic growth, which has been followed by an equivalent growth in $\mathrm{CO}_{2}$ emissions. Simultaneously, the Kyoto Protocol is based on a sharp division between developed and developing countries - the so-called Annex 1 and non-Annex 1 countries - where only the former are legally bound to cut their greenhouse gas emissions. This distinction is linked to the principle of the "common but differentiated responsibility and respective capabilities" enshrined in the 1992 Rio Convention. The principle recognizes that the traditional industrialized nations have emitted far more greenhouse gases than the developing nations and, thus, carry a historical responsibility to take upon themselves the greatest burden for action to address climate change. ${ }^{2}$ The question is whether changes in the world economy have gradually blurred the division between the Global South and the Global North, thereby legitimating claims that big developing countries should contribute legally binding emission cuts in a new global climate deal.

While the industrialized countries are responsible for roughly two-thirds of the $\mathrm{CO}_{2}$ emissions emitted since the Industrial Revolution (WDR 2010; 3), it is the poor countries and poor people, who have contributed least to the problem, that are hardest hit by climate change (IPCC 2007). They often live in high risk areas, are more dependent on climate-sensitive sectors, and have the fewest resources for coping with extreme events and adapting to changes in the climate. The inequity in the global distribution of emissions and current and future damages raises demands for justice in international climate negotiations. The term climate justice is used to frame climate change as an ethical issue and to consider how the causes and effects of climate change relate to concepts of justice and equity. ${ }^{3}$ Initially, climate justice was a concept used by religious organizations, but it has later been embraced by a much wider group of activist organizations, networks and grassroots initiatives working for social and/or environmental justice. ${ }^{4}$ In the context of international climate negotiations, climate justice entails that developed nations should take the lead in cutting emissions, to provide compensation to developing countries for the damage caused by climate change, and finally, to finance the additional costs of development resulting from the need to use low-carbon energy (Smith 2006). ${ }^{5}$

The mass media mediate between different groups of actors and competing knowledge claims, framing climate issues for politics and the public, and drawing attention to how to make sense of, and value, the changing world (Boykoff 2011; 3). How the media define climate change through different stories and frames will affect our awareness of responsibility and the kind of responses and solutions that will be carried out. The present paper explores how mainstream media construct representations of climate change and responsibility, with a particular focus on the North-South divide inherent in the negotiations during COP17 in Durban. It addresses the following questions: What climate change stories did South African and Norwegian media present to their readers during the Durban climate talks? Who had the power to define what climate change was all about? Did the negotiations spur discussions on how to transform our societies into low carbon emitters? How did they portray climate responsibility against the backdrop of shifting global geo-political and economic relations?

The empirical analysis is limited to press coverage of selected media outlets in South Africa and Norway during COP17. In the following, I give a brief description of South Africa and Norway, pinpointing some features that might affect their positions in the international negotiations. Subsequently, the South African and Norwegian media landscapes are discussed, briefly, due to considerations of space. 


\section{Two Opposing Cases: South Africa and Norway}

South Africa and Norway would appear to be extreme opposites in many respects - first and foremost, the former being a developing and the latter a developed nation. Norway is considered to be the richest country in the world and tops the list of countries judged to have the highest quality of life. ${ }^{6}$ In contrast, South Africa is a relatively developed and economically powerful country, though it faces profound poverty, unemployment, and inequality. ${ }^{7}$ Hence, the South African government needs to strike a balance when striving both to mitigate climate change and to simultaneously create jobs, reduce poverty, and close the income gap between the rich and the poor. While the South African government has ambitious emission reduction targets, fulfilment of these objectives will depend on the provision of financial resources and the transfer of technology provided by developed countries ${ }^{8}$. This is a position that South Africa shares with other emergent economies, and it constitutes some of the key issues in the climate negotiations.

Despite some obvious differences, both Norway and South Africa have ambitions to play a leading role in the international climate negotiations. Ironically, both nations are also heavily dependent on fossil fuel production. Norway is one of the largest oil exporters in the world. The petroleum sector constitutes both the backbone of the Norwegian welfare state and the major challenge in reducing $\mathrm{CO}_{2}$ emissions. South Africa has experienced a seven-fold increase in $\mathrm{CO}_{2}$ emissions since 1950 , with $90 \%$ of emissions derived from coal..$^{9}$ South Africa is ranked as the $12^{\text {th }}$ largest $\mathrm{CO}_{2}$-emitting country in the world and the largest emitting country in Africa (HDR 2007/2008).

The South African media landscape has undergone fundamental changes since the end of apartheid. Generally speaking, authoritarian control of the media as political means has given way to press freedom, globalization, and marketization. However, a free press is under pressure from the ANC government, which wants to establish a statutory Media Appeals Tribunal as an alternative to the appeal system in the current self-regulatory process (Wasserman 2012, 340). Nevertheless, today's news media are characterized by diversity, with more than twenty national daily newspapers and hundreds of community newspapers. Previous studies suggest that climate change remains an elite-oriented issue with very limited coverage in the tabloid press. ${ }^{10}$

Newspapers have traditionally had a strong position in the Norwegian media market. There are ten national daily newspapers, four regional newspapers, and more than two hundred community newspapers (Høst 2012). However, as elsewhere, the future is marked by uncertainty and concern due to Internet, which has led to a decline in circulation and falling incomes from advertisements. Today most newspapers are at least nominally independent in terms of political point of view; their news coverage is increasingly influenced by their engagement in market competition, and they have experienced considerable concentration of ownership since the 1980s. Freedom of the press is a right established in the Norwegian Constitution from 1814, and the newspapers' professional associations have developed their own declarations for safeguarding their members' independence and integrity.

\section{A Discourse Analytical Approach}

Discourse analysis can loosely be defined as a systematic and explicit study of the structures and social or cultural functions of media messages, understood as specific types 
of text and talk (van Dijk 1991; 108). It shares with framing analysis an interest in the social construction of a phenomenon by the mass media, recognizing that journalists not only convey 'objective' news stories, but also establish interpretative schemes in communication with their readers - schemes within which those stories acquire meaning. Frames can limit debate by establishing vocabulary and metaphors through which participants comprehend and discuss an issue. As defined by Robert Entman (1993):

To frame is to select some aspects of a perceived reality and make them more salient in communicating a text, in such a way as to promote a particular problem definition, causal interpretation, moral evaluation, and/or treatment recommendation for the item described.

Each article in the present study has been systematically subjected to an analytical schema, enabling me to tally selected story elements across the news stories: themes, actors, and framing. Actors are here defined as agents, which according to Chatman (1978) can be described in statements in the form of 'do' or those who act. Major agents are those who play a leading part in the stories, while minor agents are those who could have been omitted without destroying the story, but whose omission would impoverish it. An agent can take the shape of a person, a company, an organisation or a country. I complement the findings with an investigation that exposes lexical choices, something that may convey and contribute to a worldview, or a pattern of attention and perception (Alexander 2009). The analysis can mainly be divided into four parts.

(1) Distribution of main theme: Comprises the most salient information in the news item, typically contained in the headline and lead paragraph. Themes were divided into six categories, which made it possible to look at the quantitative distribution of themes across different outlets.

(2) Distribution of actors: Covers major and minor agents, but the former are given precedence. Actors are categorized into five groups, which allows detection of similarities and differences between media outlets.

(3) Vocabulary: Detects keywords or phrases that are recurrent or absent, based on the full body of newspaper texts. Determines to some extent the relevance of certain kinds of information, orientations, and responses.

(4) Framing: Identifies relevant framings in the newspaper articles, which may promote particular ways of understanding the climate problem, e.g. who is taking the lead, who is to blame, and who is responsible for dealing with climate change.

I deliberately check for textual interrelationships to ensure completeness and relate findings to an extra-textual framework for explanation, which altogether should provide a basis for solid conclusions.

\section{(a) Selection of press material}

The economic implications of the outcome of the negotiations are obvious. Hence, the present study includes prominent business papers targeting societal elites and decisionmakers. These may be said to be more independent of the effects of political power 
and more oriented towards the economic elites. Furthermore, I have chosen to cover the regional level with broad traditional quality newspaper profiles. Both the regional papers chosen exchanged materials with other newspapers within the same owner group, which means they had a larger geographical spread for some of their articles than the primary target groups.

The South African newspapers chosen were Business Day and The Mercury. While Business Day has national coverage, the Durban morning paper, The Mercury was chosen for its location, as the COP17 took place in Durban. It is aimed at middle- to upper-income readers and has no overt political leanings.

In order to make a comparative analysis, the study includes Norwegian newspapers that are comparable with the South African outlets. Hence, I have chosen Dagens Nceringsliv $(D N)$, which focuses on business reporting. It is the fifth largest newspaper in Norway and is considered independent (Høst 2012,17). Bergens Tidende (BT) is the second largest regional newspaper, based in Bergen. Traditionally, BT was a familyowned liberal newspaper, but a few years ago it became a fully owned subsidiary of Media Norway. Today $B T$ has no recognized political leanings, but it is still reckoned to carry liberal values. $D N$ and $B T$ were among the few Norwegian media outlets that sent journalists for on-the-spot coverage of COP17. Overall, the media outlets in the study, comprising different editorial profiles, were expected to provide relatively solid coverage of COP17.

The study includes press coverage beginning a few days before the summit, in order to take in some of the expectations, during the summit, and concludes with coverage extending a few days after the summit, which typically provide the first interpretations of the negotiations $(25.11 .11$ - 14.12.11). Both paper and online articles are included; duplicates have been excluded. Although images are important in communicating about climate change (even more so for tabloids and TV), the comparative design as well as time and space restrictions has led to a prioritizing of textual structures and vocabulary, omitting pictures from the analysis.

\section{Analysis}

When South Africa hosted COP17, the subject of climate change finally found its way into South African media. In Business Day and The Mercury, a total of 266 articles were published in print or online about the negotiations or related matters. This extensive coverage demonstrates that these outlets made COP17 into their chief concern at the time. The Mercury had eight dedicated journalists covering the event, while Business Day assigned five journalists to it. In contrast, the entire Norwegian press corps sent only five journalists to cover the Durban talks. Dagens Naeringsliv (DN) and Bergens Tidende (BT) published in total 62 articles, print or online, regarding COP17 or related matters. On average the South African newspapers each published five editorial articles per day, while the Norwegian counterparts each published roughly one story per day. Low expectations prior to COP17 decreased the news value of the event in many countries in Europe, and elsewhere, which were still hurting from a huge setback in public debate after the failure of the Copenhagen summit, a point reflected in Boykoff and Mansfield's media monitoring during recent years. ${ }^{11}$ 
Figure 1. Distribution of Genre in South African and Norwegian Newspapers

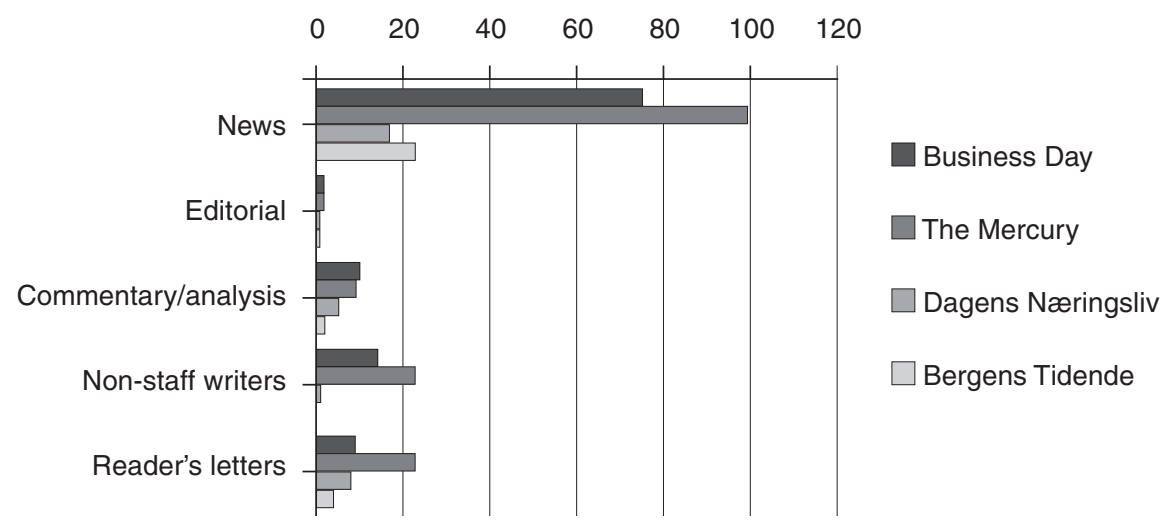

Note: $\mathrm{N}=328$.

As illustrated in Figure 1, the newspaper coverage of COP17 was dominated by the news genre, but there were also a significant number of opinionated articles written by staff. The material consists of 26 commentaries. Not surprisingly the majority of these were published by the South African outlets, but it is noteworthy that the Norwegian business paper published five commentaries. Moreover, all the newspapers had at least one editorial each.

In The Mercury seven stories were given space on the front page, which reflects the precedence of the issue. In Business Day the attention was more subdued, with only two stories on the front page. With regard to the two Norwegian newspapers, Dagens Nceringsliv made COP17 more visible than did Bergens Tidende. Five of the articles in the business paper were placed on one of the first pages of the paper and two of them actually made it onto the front page. In contrast, none of BT's articles were on the front page and most of them were in the foreign news section of the paper.

Non-staff materials and readers' letters have been excluded from the following analysis, which contains 246 articles (197 South African articles and 49 articles from the Norwegian newspapers).

\section{(a) The political game tops the list, but with large national differences}

The distribution of themes, as shown in Figure 2, reflects that COP17 was primarily a major political event. The prominence of politics was also reflected in that most of the stories that made it to the front page were concerned with political solutions, political games or positions taken by the different parties. The Norwegian newspapers were even more concerned with the political side, or to put it another way, they were less engaged with other related issues than were the South African newspapers.

Figure 2 shows that the South African outlets gave ample room to a variety of themes, including the business role in the solution, climate justice issues, and how climate change intersects with other global challenges, such as food production and energy security. Business as part of the solution was the main topic in 29 South African articles, while it figured in none of the Norwegian articles. Science and climate justice were the main themes in a total of 30 South African articles, compared to only three Norwegian articles. 
Figure 2. Distribution of Main Themes by South African and Norwegian Outlets

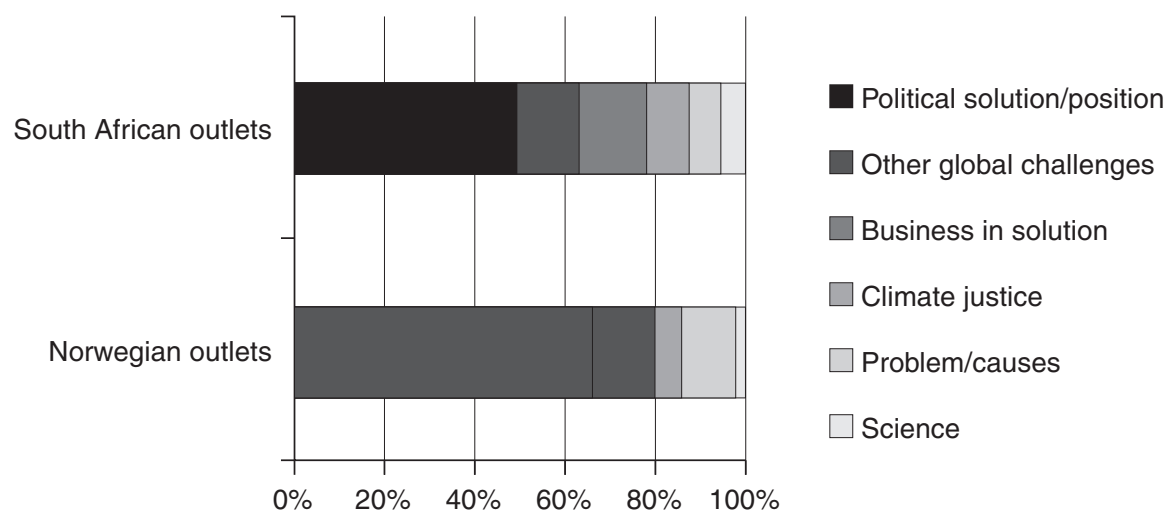

Note: $\mathrm{N}=264$.

One obvious explanation for this disparity is the scanty resources that Norwegian media put into the coverage of COP17.

The Mercury and Bergens Tidende were set apart from the business papers by reporting more on critical issues. The Mercury had three times as many articles concerned with climate justice and twice as many articles about causes triggering climate change than Business Day had - themes that often took a more critical viewpoint. It reported on the 'bad gays' like Eskom and Sasol and South Africa's reliance on coal-powered electricity, as well a presenting criticism of market-based approaches. The Mercury also stood out by giving room for Latin-American perspectives, which provided critical voices into the debate, e.g. 'Forests are not for carbon stocks' (The Mercury 02.12.11). ${ }^{12}$ Bergens Tidende was more concerned with fossil fuels as energy sources than was the Norwegian business paper, e.g. Don't let us run from the bill (BT 26.11.11). It also presented several critical articles on Norwegian energy/oil policy and investments abroad.

\section{(b) Major actors - with the power to define climate change}

As Figure 3 shows, the bulk of the media coverage was government driven, stemming from the perspectives of top politicians and government negotiators. It also reveals that the South African outlets played on a much broader range of actors, reflecting their more extensive approach to COP17, compared to the Norwegian newspapers.

The fact that activists/NGOs had the second largest share of agency points to the significance of their influence in defining climate change in the public debate. There can be different reasons why NGOs were preferred as sources over business representatives or other groups of social actors, but one explanation is news worthiness. Activists know how to comply with the media's need for images and drama (e.g., demonstrations and stunts).

However, the business papers were less concerned with NGOs than the two other papers. In fact, business representatives constituted the second largest group of agents in Business Day. In general, the South African newspapers were more attentive to private sectors playing a larger role in the solution than the Norwegian newspapers were. 
Figure 3. Distribution of Major Agents in South African and Norwegian Coverage

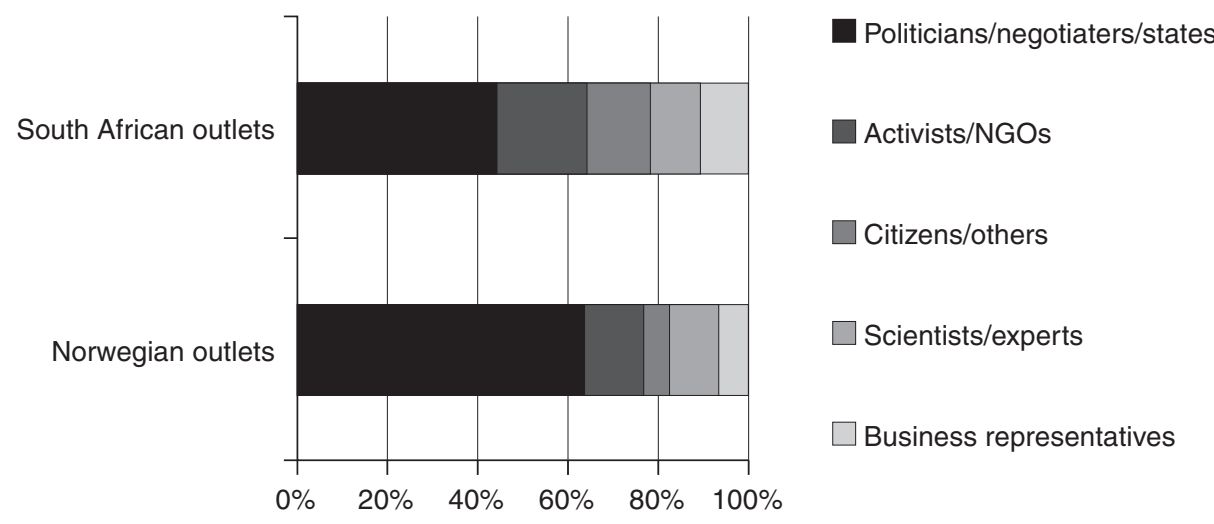

Note: $\mathrm{N}=264$.

(c) Lexical choices: what's hot and what's not?

The lexical analysis shows that the newspapers were most concerned with the building blocks of the negotiations (see Table 1). The 'Kyoto Protocol' (KP) is a buzzword in both the South African and the Norwegian outlets, followed by the 'Green Climate Fund' (GCF), both of which were core issues in the negotiations. The green fund aims at reducing emissions and adapting to climate change in developing countries. The frequent reporting on the fund should also be seen against the background of Norway and South Africa being joint leaders of a committee that was established to design the details of the fund. For the Norwegian media, the GCF is in particular often referred to by Bergens Tidende, which might reflect a larger emphasis on liberal values.

Table 1. Word or phrase in absolute occurrence (average frequency per article in parentheses). Ordered by absolute frequency rate.

\begin{tabular}{lcccc} 
& \multicolumn{2}{c}{$\begin{array}{c}\text { South African } \\
\text { newspapers } \\
(\mathrm{N}=197)\end{array}$} & \multicolumn{2}{c}{$\begin{array}{c}\text { Norwegian } \\
\text { newspapers } \\
(\mathrm{N}=49)\end{array}$} \\
\hline Energy and technology & 255 & $(1.3)$ & 95 & $(1.9)$ \\
Kyoto or Kyoto Protocol & 237 & $(1.2)$ & 104 & $(2.1)$ \\
Green Climate Fund* & 124 & $(0.6)$ & 83 & $(1.7)$ \\
Business & 84 & $(0.4)$ & 22 & $(0.4)$ \\
Adaptation/adapt & 90 & $(0.5)$ & 8 & $(0.2)$ \\
Carbon credits/-offset/-market/-trade/-finance/ & & & & \\
-project/-exchange/-price/quota trading & 22 & $(0.1)$ & 58 & $(1.2)$ \\
REDD/deforestation/forest degradation/rainforest & 29 & $(0.2)$ & 49 & $(1)$ \\
Investment(s) & 50 & $(0.3)$ & 26 & $(0.5)$ \\
Economic/financial crisis/Euro crisis & 16 & $(0.08)$ & 45 & $(0.9)$ \\
Road map; future/global/legal framework & 21 & $(0.1)$ & 39 & $(0.8)$ \\
Employment/unemployment/jobs & 45 & $(0.3)$ & 6 & $(0.1)$ \\
Sustainable/sustainability & 43 & $(0.2)$ & 1 & $(0.02)$ \\
Green economy/low carbon economy & 18 & $(0.1)$ & 1 & $(0.02)$ \\
Fair outcome/agreement/deal/solution & 10 & $(0.05)$ & 1 & $(0.02)$ \\
Common but differentiated responsibility... & 4 & $(0.02)$ & 2 & $(0.04)$ \\
\hline
\end{tabular}

* Plus search on fund, minus worldwide fund, monetary fund, adaptation fund, funding etc. 
The UN mechanism for 'Reduced Emissions from Deforestation and Forest Degradation' (REDD) had a much lower frequency rate than the GCF. Since COP13 in Bali (2007), where the Norwegian PM Jens Stoltenberg was applauded for his speech about REDD as a cheap and efficient mitigation measure, this mechanism has formed a significant part of the Norwegian international climate policy. ${ }^{13}$ Hence, it is disturbing that REDD received little and shallow coverage, stripped of critical perspectives in the Norwegian newspapers, rather it was stated briefly as an area in which progress had occurred (e.g., in Brazil). The exception is The Mercury, which brought several critical stories on REDD or REDD-plus. ${ }^{14}$ For example, 'Forest plan just a 'giant land grab' (The Mercury 03.12.11) perceived REDD as a neo-liberal, market-driven approach that leads to privatization of forests and land grabbing, thus threatening the very survival of indigenous peoples and local communities.

The importance of an international climate finance scheme and offset was prevalent in the Norwegian coverage. 'Climate credits', 'climate offset', 'climate trade' or the like occurred on average at least once in the Norwegian articles - twelve times as often as in the South African sample. Carbon credits enable developed countries like Norway to offset emissions by funding emission-reduction projects in developing countries and to trade in carbon credits earned through these activities. The majority of these articles were positive or neutral towards carbon credits, and the Norwegian business paper, Dagens Nceringsliv, accounted for most of the hits. Only The Mercury presented a handful of articles with a critical edge concerning carbon trading.

Lack of thorough and critical reporting on the applications of different mechanisms for mitigation may be a result of the climate negotiations becoming more and more complex. As Kunelius $(2012 ; 35)$ claims, climate politics has become fragmented from an overarching global concern into particular models concerning different sectors, which pose particular challenges to journalism.

'Energy/technology' was the largest buzzword across all outlets. The majority of the hits on energy or technology appeared in combination with 'clean,' 'green,' 'renewable' or 'efficiency,' drawing on a technological discourse in which a switch to renewable energy would be key to reducing emissions. This finding suggests a strong techno-optimism that the climate problem can be solved regardless of the societal context.

'Business' and 'investments' also have high frequency scores, in particular in the South African newspapers, which supports the previous finding that the South African outlets emphasized to a larger degree than their Norwegian counterparts that private sectors have a role to play in the solution. Articles containing market-oriented language in the South African outlets were often about domestic issues. The concern for how climate change mitigation may affect 'employment' was portrayed as a concern in the South African outlets, e.g. South African reliance on coal-powered electricity and the implications of a South African carbon tax on jobs. 'Green economy/low carbon economy' and 'sustainable/sustainability' received 61 hits in total, compared to only two in the Norwegian material, which implies a much greater willingness to debate these issues in South Africa. The South African media also reflected the importance of adaptation and a view that it should be just as important as mitigation.

In comparison, almost all of the Norwegian articles concerned with 'investments' or 'business' were presented in a global perspective, including world trade and restrictions, international finance of the GCF, and Norwegian investments abroad (e.g., Canada tar- 
sand projects or investments in climate initiatives in developing countries). For example, a political advisor for the Norwegian Church Aid expressed in Bergens Tidende that "Private capital is not a safe source of financing for adaption in poor and vulnerable countries" and stressed that rich countries need to "contribute with secure funding to compensate the harm they have inflicted on them" (BT 06.12.11). Also, the Norwegian outlets rarely touched upon 'employment' and when indeed 'employment' was an issue it was about the US, South Africa, and Spain. Moreover, the Norwegian articles hardly ever used the phrases 'green economy,' 'low carbon economy,' or 'sustainable.'

'Common but differentiated responsibility and capability' was rarely expressed directly. In the Norwegian material, only one article stated this principle explicitly (two hits), indeed, attacking rather than defending it due to the changed economic and geopolitical situation in the world today. The absence of 'fair outcome' in the Norwegian papers was also striking. Still, this does not mean that Norwegian climate policy does not support a fair deal, which is implicit in their support of the Green Climate Fund and a second period of the Kyoto Protocol. For example, the Norwegian PM "Stoltenberg announced in his speech that Norway will cover parts of booting-up the green climate fund" (BT 08.12.11). Nonetheless, neither the principle of 'common but differentiated responsibility' nor a 'fair deal' was the focus of attention in the coverage. These concepts also did not receive many hits in the South African newspapers compared to the output of articles.

All in all, distinct patterns of attention emerged during this lexical examination. The Norwegian coverage mainly saw climate change as a global political issue in which Norway took the role as a benefactor, expressing solidarity with developing countries. However, this image of a 'global Samaritan' overshadowed, or even obliterated how Norway should transform its own economy, industry, and infrastructure to make it a low-emission society. The South African coverage portrayed climate change more as a holistic challenge that goes hand in hand with energy and the need for creating as well as protecting jobs.

\section{(d) Framing analysis}

\section{(i) Heroes, blame and responsibility: 'China offering hint of hope'}

In one third of the Norwegian articles, Norway/EU was presented as the 'pusher countries' - together or separately - which made this the dominant frame in the Norwegian material. For example, in Europe continues alone with climate cuts (DN 10.12.11), the article underscored that the three largest emitters: China, the US and India refused to contribute, while Europe had to bear the load alone in the coming years. A handful of articles presented critical accounts of Norway's oil policy and of its role as an investor in Canadian oil sand. Environmental NGOs were important actors in drawing attention to negative aspects. For example, in Norway is a climate hypocrite, the leader of Friends of the Earth International claimed that Norway did not deserve to be named "international pusher" in the fight against climate change: "A country like Norway cannot act with one voice internationally and simultaneously continue its climate hostile policies in its own country" Bassey told Bergens Tidende (09.12.11).

Even though the EU as a 'pusher' for a global deal was acknowledged in several South African articles, the The Mercury showed more concern with South Africa as a 
host, which best can be described as a 'mediator' between between the North and the South, as expressed in an editorial on the first day of the summit:

Host South Africa has a foot in each camp, and may be one of the biggest culprits on the African continent, but could be better placed than most to bridge the gap between developed and developing worlds which lies at the heart of the COP17 conundrum (The Mercury 28.11.11).

The US and China were blamed for holding back the international climate negotiations across the news outlets. In the editorial referred to above, the newspaper wrote:

COP17 will need to put an end to the delaying tactics and pussy-footing that has characterized international climate talks up to now, and put on the table concrete and legally binding commitments from the main culprits, the US and China, to reduce emissions. The stalemate between these two countries has to come to an end if the rest of the world is to be brought on board (The Mercury 28.11.11).

However, in both the Norwegian and South African newspapers, China emerged out of the shadows as a leader in the climate field representing 'hope' and a 'potential game changer'. This distinction was also reflected in the headlines. Two headlines in The Mercury expressed positive news from China, e.g. China offers hint of hope to COP17 (The Mercury. 05.12.11) and China leads the solar revolution (The Mercury 07.12.11). In the Norwegian material, the US was only identifiable in one headline (BT 27.11.11), while China was recognized in five headlines, four of them in Dagens Nceringsliv, e.g. Progress in Chinese (10.12.11).

\section{(ii) Geo-political changes: Old division - new world}

Today's world is characterized by a fundamental shift in the global economy and the political-economic power is shifting from Northwest to Southeast. As a response to this shift a new frame emerged, which might be called the 'out-dated worldview,' and which was clearly evident in the Norwegian material. Articles within this frame challenged China, India, and other emergent economies to commit to a new global climate deal. A range of political actors from the North, e.g. the Norwegian State Secretary Kjetil Lund and the Chief Negotiator from Norway Henrik Harboe, the European Commissioner for Climate Action Connie Hedegaard, and the US Special Envoy for Climate Change Todd Stern, supported this frame. Harboe called the division between developing and developed nations, originating from the 1992 Rio Convention, 'absurd' and claimed that we needed to leave our out-dated worldview behind (DN 06.12.11). Lund also stressed that burden sharing in a new climate deal must better tackle today's emissions and those of the future, in which he argued "we can't base climate politics in this century on a worldview from last century" (BT 05.12.11).

The changing dynamics of the world were also recognized in the South African coverage, and as a consequence, what became evident was a growing sense that all countries needed to contribute in some way:

While the climate change problems were caused by an accumulation of emissions produced by developed nations from the time of the Industrial Revolution, over time responsibility had changed (The Mercury 13.12.11). 
The out-dated worldview was most frequently pronounced in the two business papers; this might be linked to the prioritizing of economic dynamics in their editorial profiles. For example, Business Day (06.12.11) writes in a news analysis that "the idea that the developing world can hold off from making commitments under any new legally binding agreement that comes out of the United Nations climate change talks, in Durban and afterwards, is fast fading." While the stalemate between the US and China in the negotiations has been seen as an obstacle for years, the 'out-dated worldview frame' upheaves the blame-frame to an ideological struggle in which the definition of developing vs. developed countries is questioned. This frame of understanding - old division, new world - provides a breeding ground for a new coalition, which is discussed below. As such, it can be seen as a result of the 'out-dated worldview' frame.

\section{(iii) New alliance crosscutting the North-South firewall}

Out of this increasingly multifarious world, a new alliance was emerging across the old North-South firewall, which had marked the Copenhagen summit two years earlier. EU was forming new allies from a group of developing countries and vulnerable island states. The alliance put pressure on China, the US and India to commit to a roadmap for negotiating a new climate deal within 2015, as can be illustrated in the following statement:

Together with a large group of developing countries and vulnerable island states, the European countries aim at a broad international climate deal in place by 2015 . In this agreement the pusher countries demand that also large emitters like China, the US, and India must commit to cut the emissions (DN 10.12.11).

The article describes how the negotiations were about to break down when the European countries and their allies protested against a final draft and demanded that a more ambitious text be carved out. The South African newspapers reported on the same alliance, but with more weight on South Africa's diplomatic skills in bringing the South and the North together in the talks.

Less ideological countries (than Venezuela, Bolivia, and Cuba) have recognised that the EU offer forms the basis of probably the only deal that can prevent Durban becoming the graveyard of Kyoto. As host and COP17 climate talks president, South Africa is more alive than most to that possibility (The Mercury 02.12.11).

The alliance, consisting of the EU, Least Developed Countries and Small Island States, and with South Africa in the driving seat, finally succeeded in steering the largest emitters to commit to negotiate a new climate deal with legal force, after negotiating two days overtime.

\section{(iv) Durban deal saves the process, but not the climate}

The outcome from COP17, the Durban Platform for Enhanced Action, elicited vastly different responses. Half of the South African articles foregrounded positive reactions while the other half gave prominence to negative responses. Key South African politicians and negotiators framed the outcome as a victory for South African leadership and used terms like 'historic,' 'precedent-setting,' or 'save tomorrow today,' while several civil society and environmental groups lambasted it as 'a disastrous outcome for the poor,' 'a face-saver for governments and the UN process,' 'nothing but hot air,' and 'another escape for corporate carbon polluters.' 
In a similar manner, the Norwegian reports strove to balance views, but displayed less overblown language than that found in the South African press. The Norwegian Minister of Environment and Development, Mr Solheim expressed that he was 'happy' that big emitters like China, India, and the US, for the first time, committed to participate in the process that should end up with a new global climate deal in 2015.

However, critical voices emphasized that it was too little, too late for slowing the pace of global warming, condemning us all to a dangerous degree of warming, endangering people living in poverty. The Nature and Youth Organization of Norway called the process a 'dangerous halt and an unforgivable betrayal of those of us who are young today'.

\section{Concluding Discussion and Outlook}

The newsworthiness of COP17 in Norwegian media had been suffering from diminishing interest ever since the Copenhagen setback. In contrast, the South African media outlets studied here made COP17 into their chief concern. For their part, they published five times more articles than the Norwegian outlets did. The South African attention can be ascribed to a stronger novelty factor, as the South African government hosted the event and the press saw COP17 as an opportunity to raise awareness about climate change.

Top politicians and government negotiators were portrayed as the key actors and were given precedence in defining the climate problem and solutions. However, the South African outlets demonstrated a greater diversity of actors, themes and assessments, including demands for a fair climate deal, how climate change intersects with other global challenges, and the role of the business community in the solution. The Norwegian press stories were minimally engaged with aspects other than the political side of the negotiations and the role of political actors in their coverage. Most striking was the lack of articles driven by business representatives, and as a consequence, business as part of the solution was ignored in the Norwegian media coverage.

The two business papers gave priority to viewing climate change through an economic lens, while the more liberal newspapers added critical voices to the debate. The latter were more concerned with fossil fuels as a cause of climate change and with climate justice issues, and more critical to market-based approaches. NGOs/activists brought critical views to such coverage and appeared to have been successful in airing their concerns regarding the negotiations. However, the analysis exposed a lack of critical views on Norwegian climate policy in the Norwegian media. While The Mercury brought out several stories critical of REDD, this was absent in the Norwegian coverage. Looking at the uncritical reporting on the issue of international climate finance schemes and offsets points to a general lack of critical distance from Norwegian international climate policy.

The South African media coverage portrayed climate change as a holistic sustainable development challenge, linking it to societal transformation, including the need to balance mitigation with energy security, employment creation, and poverty alleviation. By contrast, the Norwegian coverage mainly defined climate change as a global political issue in which Norway took the role as a benefactor, which obscured the question of how Norway should transform its own economy, industry, and infrastructure to become a low-emission society. One assumption is that South African society is accustomed to viewing a whole range of issues as development issues (e.g., health, education, and economic issues), while the Norwegian society is used to viewing (sustainable) develop- 
ment as a targeted pursuit developing countries are concerned with. An intriguing question is whether the developing/development dichotomy is keeping actors from seeing sustainable development as an on-going process that concerns all nations of the word.

Both the South African and the Norwegian newspapers studied here blamed the US and China for stalling the negotiations. However, China was also viewed as an emerging leader in the climate field, representing 'hope' and a 'potential game changer'. There are at least two reasons for this shift. China has shown convincing initiatives to reduce carbon intensity by staking out a greener course and was less persistent in demanding it be treated the same as less developed countries. Interestingly, both the South African and the Norwegian outlets portrayed their own respective governments as the heroes of the process. In the Norwegian papers, Norway together with the EU was portrayed as the 'pusher countries.' In the South African newspapers there was a tendency to portray South African as a 'mediator' that was needed to bring the global South and the global North together in the talks.

By defining climate change as a global political issue, Norway can appear as a global Samaritan and a pusher country for a new global deal. As such, the positive attention given to the Green Climate Fund may adhere to what Eide refers to as the dominate discourse, which is the neo-liberal development paradigm, leaning on a pragmatic North-South perspective and motivated by realistic rather than idealistic incentives (Eide 2012; 101).

COP17 became an era of struggle and contestation of worldview. It was claimed that the world cannot base a new global climate deal on an old worldview in which only the Western industrialized countries contribute with legal commitments to cut their emissions. The 'out-dated worldview frame' challenges the burden sharing roles of the emergent economies to better reflect today's emissions and those of the future. A reframing of the worldview is probably inevitable in order to move the international negotiations forward and in dealing with the physical climate problem. However, in an eager attempt to get all major emitters on board, there is a danger of ignoring 'the common but differentiated responsibilities and capabilities' principle, which may be an attempt to excuse rich industrialized countries from their responsibility after 150 years of benefitting from fossil-fuel-driven development.

Looking ahead, further media analysis is crucial to understanding how political representations in international negotiations will develop. In the coming years, this will develop against a backdrop of the changing geo-political landscape; in particular, it will be important to find out how the 'out-dated worldview frame' might impact on negotiating positions and about the opportunity of negotiating a fair and efficient climate deal. Moreover, the large difference seen between South African and Norwegian coverage of society transformation suggests the importance of further investigation of drivers toward, and barriers against, engaging constructively with climate transformation in different contexts and how this debate is promoted or restricted in the media.

\section{Notes}

1. Department of Information Science and Media Studies, University of Bergen.

2. See WDR 2010 and HDR 2011 for overview of country's emissions.

3. Climate justice is also used with reference to legal systems: http://www.climatelaw.org/. See also http:// en.wikipedia.org/wiki/Climate_justice.

4. See for example Bond 2012, 185-214. 
5. For a more detailed review of climate justice and climate impacts on South Africa, see Johannessen 2013.

6. http://www.mapsofworld.com/world-top-ten/world-top-ten-quality-of-life-map.html

7. WDR 2010; 381, QLFS_Q4: 2011.

8. http://unfecc.int/documentation/documents/advanced_search/items/6911.php?priref=600006178\#beg

9. http://cdiac.ornl.gov/trends/emis/tre_saf.html

10. Orgeret 2010; 294, Orgeret \& d'Essen 2012; 263.

11. http://sciencepolicy.colorado.edu/media coverage/

12. See also Johannessen 2013 for a more detailed analysis on the South African media.

13. See Eide (2012; 87-102) for a more detailed analysis of media coverage of REDD.

14. http://www.un-redd.org/AboutREDD/tabid/102614/Default.aspx

\section{References}

Alexander, R.J. (2009) Framing Discourse on the Environment: A Critical Discourse Approach. London: Routledge.

Bond, P. (2012) Politics of Climate Justice. South Africa: University of KwaZulu-Natal Press.

Boykoff M.T. (2011) Who Speaks for the Climate? Making Sense of Media Reporting on Climate Change, 3. UK: Cambridge University Press.

Chatman S. (1978). Story and Discourse: Narrative Structure in Fiction and Film. Ithaca, NY: Cornell University Press.

Eide E. \& Kunelius R. (2010) Global Climate - Local Journalisms. A Transnational Analysis of Media Making Sense of Climate Summits. Dortmund: Projekt Verlag.

Eide, E. \& Kunelius R. (eds.) (2012) Media Meets Climate. The Global Challenge for Journalism. Göteborg: Nordicom.

Entman R.M. (1993) Framing: Towards Clarification of a Fractured Paradigm. Journal of Communication $43(4), 51-58$

Giddens, A. (2009) The Politics of Climate Change. Cambridge: Polity Press.

Hulme, M. (2010) Why We Disagree about Climate Change. Cambridge: Cambridge University Press.

Human Development Report (2007/2008) Fighting Climate Change - Human Solidarity in a Divided World. New York: UNDP.

Høst, S. (2013) Avisåret 2012. Rapport Nr. 37. Volda: Høgskulen i Volda.

Intergovernmental Panel on Climate Change (IPCC) Fourth Assessment Report Part 1 (2007).

Johannessen, J. (2013) Climate Change, Poverty and Climate Justice in South African Media: The Case of COP17. South African Journal on Human Rights 29(1), 32-60.

Kunelius R. (2012) Durban Editorials and the Discursive Landscape of Global Climate Politics, in Eide, E. \& Kunelius R. (eds.) Media Meets Climate. The Global Challenge for Journalism, 31-49. Göteborg: Nordicom.

Orgeret, K.S. (2010) South Africa: A Balancing Act in a Country of (at least) Two Nations. In E. Eide, R. Kunelius \& V. Kumpu (eds.) Global Climate - Local Journalisms, 263-281. Freiburg: ProjectVerlag.

Orgeret, K.S. \& d'Essen, C. (2012) From COP15 to COP17. Popular Versus Quality Newspapers Comparing Brazil and South Africa. In E. Eide \& R. Kunelius (eds.) Media Meets Climate. The Global Challenge for Journalism. Göteborg: Nordicom.

Quarterly Labour Force Survey, QLFS_Q4: 2011. South Africa.

van Dijk, T.A. (1991) The Interdisciplinary Study of News as Discourse. In K.L Jensen. \& N.W. Jankowski (eds.) A Handbook of Qualitative Methodologies for Mass Communication Research, 108-121. London: Routledge.

Smith, M.D. (2006) Just One Planet. Poverty, Justice and Climate Change. UK: Intermediate Technology Publications Ltd.

Wasserman, H. (2012) China in South Africa: media responses to a developing relationship. Chinese Journal of Communication, 5(3), 336-354.

World Bank. Development Report (2010) Development and Climate Change. Washington, DC: World Bank.

Jill Johannessen, Dr.polit in Sociology, Postdoc, Department of Information Science and

Media Studies, University of Bergen, jillprivat@icloud.com 